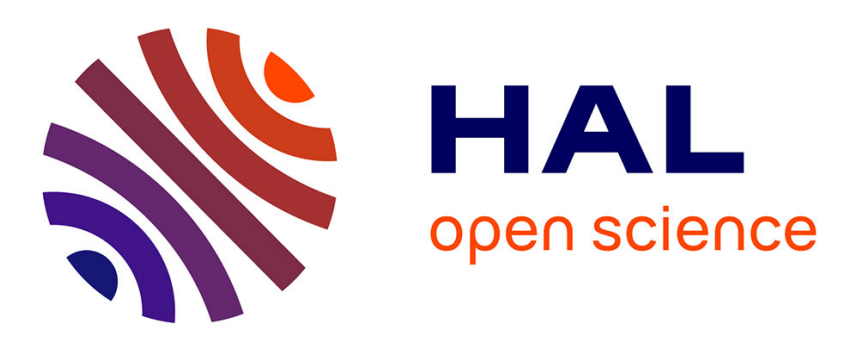

\title{
The Pros and Cons of Higher Transparency: The Case of Speculative Attacks \\ Jean-Pierre Allegret, Camille Cornand
}

\section{To cite this version:}

Jean-Pierre Allegret, Camille Cornand. The Pros and Cons of Higher Transparency: The Case of Speculative Attacks. Recherches Economiques de Louvain - Louvain economic review, 2006, 72 (3), pp.215-246. halshs-00137469

\section{HAL Id: halshs-00137469 \\ https://shs.hal.science/halshs-00137469}

Submitted on 20 Mar 2007

HAL is a multi-disciplinary open access archive for the deposit and dissemination of scientific research documents, whether they are published or not. The documents may come from teaching and research institutions in France or abroad, or from public or private research centers.
L'archive ouverte pluridisciplinaire HAL, est destinée au dépôt et à la diffusion de documents scientifiques de niveau recherche, publiés ou non, émanant des établissements d'enseignement et de recherche français ou étrangers, des laboratoires publics ou privés. 


\title{
The Pros and Cons of Higher Transparency: The Case of Speculative Attacks*
}

\author{
Jean-Pierre Allegret \\ GATE, UMR 5824 CNRS, Université Lyon 2 et ENS LSH \\ École Normale Supérieure Lettres et Sciences Humaines GATE - CNRS \\ Bureau R131 \\ 15, Parvis René Descartes BP 700069342 Lyon cedex 07 FRANCE \\ allegret@gate.cnrs.fr \\ and \\ Camille Cornand \\ R 410, Financial Market Group \\ London School of Economics and Political Sciences \\ Houghton Street, London WC2A 2AE, UNITED-KINGDOM \\ cornand.camille a, libertysurf.fr
}

Final version - January 2006

\begin{abstract}
The aim of this paper is to evaluate to what extent more transparency can reduce the occurrence of speculative attacks. It proposes a survey of the literature about the pros and cons of transparency on the exchange rate market, which is one of the main pillars of the new international financial architecture. The effects of transparency are shown to be ambiguous both from a theoretical and empirical point of views. However, the imperfect connection resulting from the confrontation between theory and empirics suggests that some new insights are necessary in order to better catch stylised facts on the one hand and to better evaluate the theory on the other, as has been done in recent literature. This leads to new proposals for economic and informational policies.
\end{abstract}

\section{Résumé}

Cet article analyse dans quelle mesure une transparence informationnelle plus élevée réduit la probabilité d'attaque spéculative. La transparence est devenue l'un des piliers de la nouvelle architecture du système financier international proposée par les institutions internationales après les crises de change des années 90 . L'article propose une recension de la littérature permettant d'identifier les arguments favorables et défavorables à une transparence accrue. On montre que les effets d'une plus grande transparence sont ambigus, et ce, à la fois d'un point de vue théorique et empirique. Cependant, l'imparfaite concordance entre les conclusions théoriques et les résultats empiriques nous conduit à proposer de nouveaux cadres informationnels, tels qu'ils découlent de la littérature la plus récente, afin, d'une part, de mieux rendre compte des faits stylisés et, d'autre part, de mieux évaluer les théories sous-jacentes.

Keywords: Transparency, Public and private information, Speculative attack, Coordination games, Common knowledge.

JEL Classification: C73, D82, F31.

\footnotetext{
* We thank the participants to the 2004 International Conference on Coordination Failures in Paris and more especially Frank Heinemann as well as an anonymous referee and the editor of Louvain Economic Review Michel De Vroey for very useful comments. All errors remain our own responsibility.
} 


\section{Introduction}

Since the 1990's, the international financial system has been hit by several self-fulfilling and almost unpredictable speculative crises. The latter have shown the deficiency of pertinent information conveyed to the market. International financial institutions' response to these crises has been to increase the flow of accurate and comprehensive information and to enhance transparency. Indeed, higher transparency would improve the effectiveness of market discipline and reduce self-fulfilling speculative attacks. Therefore, when coping with such crises, an important question is to evaluate to what extent more transparency can lead to minimize speculative attacks. This is the main aim of this paper. It proposes a survey of the literature about the pros and cons of transparency. It contributes both theoretically and empirically- to the debate on the new international financial architecture, the transparency of which is one of the main pillars.

If more information is suitable in a pure decisional context, we can wonder about its contribution in a strategic environment. In studying transparency policy on the exchange rate market, we consider the impact of transparency on the beliefs of the agents. Does transparency imply common knowledge? And does common knowledge reduce or increase the likelihood of a speculative attack? A fact is common knowledge when everyone knows it, when everyone knows that everyone knows it, and so on. In coordination games assuming common knowledge, there are multiple equilibria as in second generation speculative attack models ${ }^{1}$. As a consequence, the selection of a particular equilibrium becomes unpredictable, and then the impact of transparency on the likelihood of speculative attacks is not relevant. Indeed, any exogenous event can drive a speculative attack.

To compare the impact on players' behaviours of different informational settings, it is necessary to remove the common knowledge assumption. This is precisely the purpose of global games models ${ }^{2}$ and more generally recent coordination games in incomplete information applied to speculative attacks. Global games assume common knowledge of rationality, but there is no common knowledge of payoffs. Each player must face two types of uncertainty:

- fundamental uncertainty about the value of the state variable ${ }^{3}$; such an uncertainty affects the payoff relevant state of nature;

- strategic uncertainty based on the lack of common opinions about the state variables; such an uncertainty concerns the actions of other agents, resulting from a situation of strategic complementarities between players: the greater the number of other participants choosing the same decision, the greater the payoff for a particular player.

\footnotetext{
${ }^{1}$ For speculative attack models, see the critic of the Obstfeld's model by Morris and Shin (1998). For an overview, see Myatt, Shin and Wallace (2002).

${ }^{2}$ Morris and Shin (2003) define global games as "games of incomplete information whose type space is determined by the players each observing a noisy signal of the underlying state" (p.56). A precise presentation of global games models is beyond the scope of this paper. For an overview, see Morris and Shin (2003).

3 A state variable is a specific characteristic of the environment, which affects the payoffs of players. For instance, in a speculative attack game, the size of the central bank's foreign exchange reserves is a state variable for speculators.
} 
In this environment, global games describe a situation in which rational behaviour "depends not only on economic agents' beliefs about economic fundamentals, but also depends on beliefs of higher order -that is, players' beliefs about other players' beliefs, players' beliefs about other players' beliefs about other players' beliefs, and so on" (Morris and Shin (2003) p.56).

In order to determine the impact of information disclosure on the beliefs of the agents, two types of information are traditionally distinguished. First, public information consists of signals on the level of fundamentals which are commonly shared by all traders. In principle, it should help market participants to take a better decision, which is a decision more linked to the fundamental situation of the economy. "Virtually, any event which is publicly observable and affects economic fundamentals [...] could be classified under that label" (Prati and Sbracia (2002) p.7). Second, private information "refers to pieces of knowledge that may be different from one trader to the next" (Bannier (2005a) p.2).

Using this basic framework for our analysis, transparency can be defined as an increase in the precision of information: transparency in the public signal(s) and transparency in the private signal(s) (which are always defined by an extreme precision on the concerned signals of different nature). This issue has direct implications in terms of economic policy. The possibility to analyse the role of information disclosure is relatively recent. On the one hand, the confrontation between zones with unique versus multiple equilibria leads to the determination of situations in which the economy is stable versus unstable. On the other hand, the existence of a unique equilibrium in coordination games gives us the opportunity to study the impact of information owing to comparative statics.

However, those informational structures do not go without any problems. Especially, it seems that those analyses go too far in assuming that information is decentralised among atomised agents (Jeanne, 2000). The main assumption of such models is to consider that information is essentially private. Yet, on the exchange rate markets, information on economic fundamentals is typically public. Such a criticism is at the core of our analysis. We therefore suggest to model the informational environment to which markets participants are submitted in a more appropriate fashion, by questioning the strict dichotomy between private information on the one hand and public information on the other. For example, we want to be able to answer the following questions:

- How should public information be disclosed without becoming common knowledge?

- Doesn't the provision of publicly announced information by the central bank necessarily lead to the formation of subjective and thus private beliefs?

- Where is the limit between public information and private information both on a theoretical and empirical (or practical) side?

This paper aims at going beyond those contradictions and at better evaluating transparency policy by synthesising and confronting theoretical and empirical works on transparency on the exchange rate market. Thus, the remainder of the paper is structured as follows. Section 1 develops theoretical results on transparency coming from a coordination game analysis; section 2 focuses on empirical studies 
relying on the previously mentioned theoretical frameworks. Section 3 confronts theory and empirics and analyses how recent developments better catch stylised facts. This enables us to propose new insights for economic and informational policies.

\section{Optimal Transparency Policy: Theoretical models}

Theoretical models of coordination games with incomplete information dedicated to speculative attacks suggest that transparency has ambiguous consequences on the stability of markets. This conclusion is based on the difference of nature between public and private information in decentralized markets. In spite of its coordination potential, public information may be destabilising. In this perspective, an optimal transparency policy does not necessarily mean complete transparency. We study the optimal transparency policy by considering the impact of higher transparency on the probability of a speculative attack. Three environments can be distinguished: (i) the public information case as a benchmark situation, (ii) the private information context, and (iii) the simultaneous public and private information framework.

1.1 The optimal transparency under public information

In the standard model of Obstfeld $(1986,1996)$, the fundamental state of the economy is perfectly known by the agents: it is common knowledge. In this sense, there is full transparency. The model leads (in the intermediate region) to self-fulfilling belief equilibria.

The fundamentals of the economy are characterized by the parameter $\theta$, which is not observed by the agents:

$\theta \sim \mathrm{N}\left(y, \tau^{2}\right)$

The agents only have expectations about $\theta$ in the form of a normal probability distribution with mean $y$ and variance $\left(\tau^{2}\right)$. As a consequence, the public signal $y$ is given by a noise $\eta$, as follows:

$y=\theta+\eta$, with $\eta \sim \mathrm{N}\left(0, \tau^{2}\right)$.

In the formal framework, the variable $y$ is thus common knowledge and $\mathrm{E}(\theta y)=y$.

Multiple equilibria can be interpreted as destabilizing for the economy as a crisis can occur or not, just depending on the beliefs of market participants. Following Prati and Sbracia (2002), it appears that when the precision of public information increases, its effect on the likelihood of speculative attack depends on the expected fundamentals: if they are sufficiently good (bad), then speculative attacks are less (more) likely. Indeed, precise public information means that speculators are more confident about the fact that the actual fundamentals come close to their ex post expectation. 


\subsection{The optimal transparency under private information}

Morris and Shin (1998) consider the impact of the sole private information on the behaviour of speculators. The state $\theta$ of the economy is assumed to be uniformly distributed on a large support (say R):

$$
\theta \sim \mathrm{U} \text { on } \mathfrak{R} \text {. }
$$

Thus signals are also uniformly distributed as follows:

$X_{i}=\theta+\varepsilon_{i}$, with $\mathcal{\varepsilon}_{i} \sim \mathrm{N}\left(0, \sigma^{2}\right)$.

In such a context, they show that more precise private information -that is, more transparency defined, in that case, as a low variance in private information- reduces the probability of speculative attacks.

To minimise the probability of speculative attacks, the government should provide the best possible private information but avoid common knowledge because of the danger of multiple equilibria (Heinemann and Illing (2002)). The link between transparency and the likelihood of speculative attack rests on the following assumption: payoffs attached to a speculative attack depend negatively on the fundamentals. The lower the fundamentals, the higher the payoffs in case of a successful attack. Speculators bear only transaction costs if attacks fail. First, higher transparency, in the sense of more precise private information, helps to reduce market uncertainty and therefore reduces incentives for speculative attacks: multiplicity of equilibria is less likely, the higher the precision of private information. Second, higher transparency helps to reduce the probability of attacks even if the equilibrium is unique. Precise private information -and a low degree of common beliefs- leads to a unique equilibrium with a low probability of attack if it indicates a rather good fundamental state. On the contrary, a non-transparent policy might trigger an attack even when fundamentals are rather good. When fundamentals are bad, the authorities have an incentive to provide biased information overoptimistic information about the state of the economy- in the hope to decrease the probability of an attack. In fact, such behaviour is counterproductive: knowing that good signals are unreliable, speculators attack the currency where they would not have attacked if the same signals had been more reliable (Cheli and Della Posta (2002)).

Transparency results from public announcements about the state of fundamentals. However, public announcements are common knowledge. Hence, Heinemann and Illing (2002) wonder how private information should be disclosed without becoming common knowledge. They claim that a way of achieving such a result would be to give to any agent reliable information when they ask for it without announcing it publicly. Speculators could never be sure that the other agents possess the same information as them. Similarly, reducing the precision of public announcements could avoid high degrees of common beliefs. Another possibility would consist in adopting a decentralised approach. In presence of excellent but costly information, the probability that two agents use exactly the same 
source could be sufficiently small to avoid the degree of common beliefs required for multiple equilibria.

1.3 The optimal transparency under public and private information

The impact of both public and private information on the decision of economic agents has been explored by Morris and Shin (2004). In the model,

$\theta \sim \mathrm{N}\left(y, \tau^{2}\right)$

where $y$ is common knowledge.

Agents receive independently and identically normally distributed signals $X_{i}$ on the fundamentals:

$X_{i}=\theta+\varepsilon_{i}$, with $\varepsilon_{i} \sim \mathrm{N}\left(0, \sigma^{2}\right)$.

As $\mathrm{E}\left(\theta X_{i}, y\right)=\frac{\tau^{2} X_{i}+\sigma^{2} y}{\tau^{2}+\sigma^{2}}$, the impact of transparency on the likelihood of speculative attacks depends mainly on the relative precision of public and private signals.

Morris and Shin (2004) find that the effects of private and public signals' precision are at best ambiguous. Indeed, the difference between private and public information leads to some interesting results. In the presence of private information about the underlying fundamentals, greater precision of public information does not always lead to a better situation. Global game models show that if the precision of public information is large compared to the precision of private information, then multiple equilibria and inefficiency can appear. That means that the level of fundamentals does not determine whether an attack or a non-attack equilibrium prevails. This result has been extended and the model also presents some variants.

\subsubsection{Extensions and applications}

Metz (2002), Bannier and Heinemann (2005) and Prati and Sbracia (2002) propose an application of the debt crisis model of Morris and Shin (2004) to a currency crisis model. They deduce policy implications from such a framework.

Metz (2002) shows that with both public and private signals there exists an interaction between the two types of information: public and private information can have opposite effects on the prior probability of a crisis, depending on the prior mean of fundamentals. In the case of a bad fundamental state of the economy, the more precise public information and the less precise private information, the higher is the probability of a speculative attack. On the contrary, in a situation of good fundamentals a higher precision of the public signal and a lower precision of the private signal lead to a reduction in the probability of crisis.

Bannier and Heinemann (2005) analyse the problem of information disclosure when a central bank is threatened by a speculative attack on the peg by traders. Information policy by the government is based on the dissemination of individual signals on the realized state of the economy to the agents. In so far as ex post beliefs differ among agents, this information is private. The government can choose 
the degree of precision of the information he discloses. High precision means that private agents are able to predict central bank policy. Transparency is described as the precision of the "posterior information" on the realized fundamental state. The main result of their model suggests that complete transparency is not necessarily desirable. More precisely, the optimal degree of transparency depends on the "market sentiment", that is the a priori expected value. Market sentiment represents public information to the extent that it is a common belief about the reaction of the central bank faced to market positions. When the market is sufficiently pessimistic, that is when the prior mean of the economic performance is under a certain threshold (meaning prior bad fundamentals), the government should commit itself to disclose private information with maximal precision. On the contrary, when the market is sufficiently optimistic, i.e. for good prior expectations on the fundamentals, the optimal policy depends on the variance of fundamentals. On the one hand, a low variation expected by the agents requires that the authorities disseminate private information with the lowest possible precision. The rationale for such behaviour is for the authorities to avoid speculative attack triggered by selffulfilling beliefs. On the other hand, when the market expects a high variation, and for an increasing variance of fundamentals, then the optimal degree of transparency rises.

These results are explained as follows. If agents anticipate that the state is bad, they are strongly inclined to attack the currency. The fact to have no information incites agents to attack the exchange rate regime: without private information, the threshold of attack would be high, even if the fundamental state was much better than the expected state; with private information, agents can suppose that the state could be better. The central bank must then commit itself to disclose private information: agents become aware of the good states and will avoid the attack, if there is effectively a good fundamental state. If the state were bad, they would attack anyway (it is not possible to avoid an attack in a situation of bad fundamentals). Conversely, if prior expectations are good (high expectations of non attack), agents avoid the attack; giving private information cannot ameliorate the state of things. It is thus preferable for the central bank not to disclose any private information on the posterior state of fundamentals. In other words, if the market considers that the economy is in a fundamentally good state, the central bank should commit itself to a low precision of private information so as to reduce the probability of an attack.

Prati and Sbracia (2002, p.4) also study "the effects of the precision of public and private information on the share of speculators attacking the currency". The influence of the precision of private information rests on the distinction between direct and indirect effects. On the one hand, as the precision of private information is inversely related to the dispersion of private signals received by speculators around the actual fundamentals, it directly influences the likelihood of speculative attacks. On the other hand, through the ratio between the precision of public information and the precision of private information, this latter exerts an indirect influence. When a speculator decides to attack or not, he takes into account not only his expectations about the fundamentals, but also the extent to which his beliefs are shared by the other speculators. The precision ratio represents such an estimation of the 
shared beliefs. A high ratio tends to increase the "degree of aggressiveness" (Prati and Sbracia (2002) p.6) because each speculator knows that the others formed their expectations by giving a large weight to the public signal. Again, the impact on the likelihood of speculative attacks depends on the expected fundamentals:

- when expected fundamentals are good, a high precision ratio decreases the likelihood of speculative attacks. Indeed, all speculators know that this good public signal is determinant in the formation of expectations by the others;

- when expected fundamentals are bad, the reverse occurs.

In terms of optimal transparency policy, the precision ratio leads to the following implications: when the expected fundamentals are good (respectively bad), authorities should be more (i.e. high ratio) (respectively less (i.e. low ratio)) transparent (i.e. more precise in the disclosed public information). In the latter case, relatively precise private information makes coordination between speculators (on attacking the currency) more difficult: each speculator is uncertain about the extent to which his beliefs are shared by the others.

1.3.2 Variant: fundamental uncertainty and strategic certainty

Sbracia and Zaghini (2001) propose a model in which all agents have the same imperfect public signal about the fundamentals. In this sense, there is no strategic uncertainty. At the same time, they assume that public information is not completely precise. As a result, fundamental uncertainty remains in the market.

Sbracia and Zaghini (2001) show that the transparency policy depends on the fundamental states of the economy. Indeed, "providing public information seems to be more convenient when fundamentals are "rather bad" than when fundamentals are "rather good"”" (Sbracia and Zaghini (2001) p.205). When fundamentals are good, it is optimal for speculators holding only private information not to attack. Indeed, their expected payoff from a successful attack is small because, taking into account the level of fundamentals, it appears that the share of speculators attacking the currency to force the government to abandon the peg is high. In other words, when fundamentals are good, the "amount of coordination" required to attack is high. The release of public information eliminates the uncertainty on the other players' actions because each agent can precisely establish the information received by the others. Public information then gives speculators the possibility to gain a small positive payoff by attacking the currency because speculators have the opportunity to coordinate between them on such an equilibrium. When fundamentals are bad, the payoff associated to a successful attack increases. Thus the level of required coordination decreases. In this context, taking into account the small "coordination effort" to produce the collapse of the peg, speculators holding only private information attack the currency. The diffusion of public information could refrain themselves from attacking the currency. 


\subsubsection{A beauty contest version}

Morris and Shin (2002) underline that one of the drawbacks of this previously mentioned global game literature is that the study of the role of public information (owing to comparative static) is rendered difficult by the complex effects arising from the interrelation between better fundamental information and changes in strategic uncertainty. They thus propose a more simple beauty contest model that avoids such a drawback by giving equilibrium uniqueness for any parameter of the model. They are able to study the role of the precision of private and public signals on welfare. They show that the noise in the public signal is given more weight than the noise in the private signal, which reflects the coordination motive of the agents and the disproportionate influence of the public signal in influencing the agents' actions. In terms of welfare effects, they get the following result. While welfare is unambiguously increasing in the precision of the private signals, increased precision of public information is beneficial only when the agents' private information is not very precise. Therefore, "when the private sector agents are already very well informed, the official sector would be well advised not to make public any more information, unless they could be confident that they can provide public information of very great precision" (Morris and Shin (2002) p.19). The rationale for such a conclusion is that agents "overreact" to the public signal while suppressing the information content of the private signal. This underlines the importance of shared knowledge ${ }^{4}$.

Angeletos and Pavan (2004) challenge the conclusions of Morris and Shin (2002). Considering economies with increasing returns to scale, they find that the precision of public information is always welfare increasing. The result is conducted by the different notion of individual utility. While in Morris and Shin the payoff of a player decreases with the distance between his own action and the action of others, but this distance is irrelevant from a social perspective, Angeletos and Pavan consider environments in which there is complementarity at the social level so that coordination is socially valuable. However, on financial markets, it is socially desirable to avoid any form of overreaction, so that it seems to be always better to evaluate a currency or a firm in terms of the fundamental state of the economy rather than the beliefs of market participants.

\subsection{Synthesis of theoretical results}

Table 1 presents a summary of the main results of the models studied above. Traditional models on speculative attacks assume common knowledge on fundamentals. In this context, as an attack is triggered by any event, no policy prescription can be deduced from the costs and benefits of higher transparency. When there is no common knowledge, the main result of the literature on the subject is

\footnotetext{
${ }^{4}$ Commenting upon Morris and Shin (2002), Svensson (2005) shows very intuitively that this paper makes in fact a good case for transparency. Numerical conditions under which an increasing transparency reduces welfare require that the precision of public information is much smaller than the precision of private information, which seems unreasonable. However, Morris, Shin and Tong (2005) show that if private and public signals are correlated, the potentially disturbing effects of public information remain crucial, even if public information is more precise than private signals.
} 
to stress the ambiguous effect of higher transparency. The important point is the following: a priori, it is impossible to be sure that higher transparency could reduce the likelihood of speculative attacks.

Table 1 Theoretical predictions: summary

\begin{tabular}{|c|c|c|}
\hline $\begin{array}{l}\text { Informational } \\
\text { structure }\end{array}$ & $\begin{array}{l}\text { Basic model, Definition } \\
\text { and Equilibrium }\end{array}$ & Consequences in terms of economic policy \\
\hline $\begin{array}{l}\text { Public } \\
\text { information } \\
\leftrightarrow \text { Common } \\
\text { information } \\
\text { (CI) }\end{array}$ & $\begin{array}{l}\text { Obstfeld (1996): } \\
\text { Common knowledge on } \\
\text { economic fundamentals } \\
\Rightarrow \text { Multiple equilibria. }\end{array}$ & $\begin{array}{l}\text { Doubts about the advantages of public information } \\
\text { disclosure as advocated by International Financial } \\
\text { Institutions. } \\
\text { Multiple equilibria } \Rightarrow \text { no policy prescription. }\end{array}$ \\
\hline $\begin{array}{l}\text { Private } \\
\text { information } \\
\text { (PI) }\end{array}$ & $\begin{array}{l}\text { Morris \& Shin (1998): } \\
\text { Sufficiently precise } \\
\text { private signal } \Rightarrow \text { Unique } \\
\text { equilibrium (in a global } \\
\text { game framework). }\end{array}$ & $\begin{array}{l}\text { Heinemann \& Illing }(2002) \text { : } \\
\uparrow \text { Precision of private information } \Rightarrow \downarrow \text { Probability of } \\
\text { attack. }\end{array}$ \\
\hline $\begin{array}{l}\text { Public and } \\
\text { private } \\
\text { signals } \\
\leftrightarrow \\
\text { Simultaneous } \\
\text { private and } \\
\text { common } \\
\text { signals game } \\
\text { (PCS) }\end{array}$ & $\begin{array}{l}\text { Morris \& Shin (2004): } \\
\text { Sufficiently precise } \\
\text { private information } \\
\text { compared to public } \\
\text { information } \Rightarrow \\
\text { Equilibrium uniqueness } \\
\text { (in a global game } \\
\text { framework). }\end{array}$ & $\begin{array}{l}\text { Morris \& Shin (2004): } \\
\uparrow \text { Precision of private and public signals } \Rightarrow \text { Ambiguous } \\
\text { effect. } \\
\text { Metz (2002): } \\
\text { Bad state: } \uparrow \text { Precision of public information }+\downarrow \\
\text { Precision of private information } \Rightarrow \uparrow \text { probability of } \\
\text { attack. } \\
\text { Good state: conversely. } \\
\text { Bannier \& Heinemann (2005): Each time the prior } \\
\text { probability of the mean of economic performance is } \\
\text { under a certain threshold, the central bank should engage } \\
\text { itself on the maximal risk and diffuse private information } \\
\text { with a maximal precision; and conversely. } \\
\text { Sbracia \& Zaghini (2001): } \\
\text { Bad state: } \uparrow \text { Precision of public information } \Rightarrow \text { multiple } \\
\text { equilibria } \Rightarrow \text { a chance to avoid attacks. } \\
\text { Good state: } \uparrow \text { Precision of public information } \Rightarrow \downarrow \text { risk } \\
\text { of attack. } \\
\text { Morris \& Shin (2002): } \\
\uparrow \text { Precision of private signal } \Rightarrow \uparrow \text { Welfare. } \\
\uparrow \text { Precision of public signal } \Rightarrow \text { Ambiguous effect on } \\
\text { welfare: } \\
\quad+\text { Not precise private information } \Rightarrow \uparrow \text { Welfare } \\
\quad+\text { Precise private information } \Rightarrow \downarrow \text { Welfare. }\end{array}$ \\
\hline
\end{tabular}


The positive effect of higher transparency depends on the relative precision of public and private information. Recall that if higher transparency raises the precision of public information relative to private information, this creates a situation of common knowledge and market instability.

We stress that transparency policy of international financial institutions have to face a dilemma. On the one side, increasing transparency helps coordination. On the other side, increasing transparency has the inconvenience of generating overreaction because transparency makes information tend toward common knowledge. Now this dilemma is particularly critical for public information. In providing a focal point for the beliefs of the agents, public information facilitates coordination. Indeed, contrary to private information, public information exerts a specific influence on higher-order uncertainty. It allows a market participant to make some assumptions about the other participants' actions. This characteristic results from the fact that public information provides information about what the other participants have observed relatively to the own private signal of a particular player. As a result, the latter can infer from public information what other players are likely to play. In other words, if private information conveys information only about the state of the economy, public information fulfils the two roles. It is "a double-edge instrument" (Morris and Shin (2002) p.1532). Some papers show that this effect is strengthened or to the contrary reduced according to the market sentiment or the initial state -bad or good- of fundamentals.

\section{Empirical Evidence of Transparency}

Empirically, the impact of public and private information on the coordination of agents and more generally on welfare has been rarely explored in econometric studies and a bit more in experimental economics analyses. There exists however no systematic empirical study of the impact of transparency.

We are particularly interested in the practical efficiency of transparency, which constitutes one of the major questions in the debate on the reform of the international financial architecture. Firstly, a critical synthesis of the econometric studies on real data is proposed. Secondly, the results stemming from data of experiments are envisaged. The advantages that presents the experimental study relatively to analyses of "real" data are numerous: the analysis of the coordination behaviour in the laboratory allows to control the various variables and to obtain unobservable data in the reality. However, the reproduction of a situation of attack in the laboratory presents the inconvenience not to correspond strictly to the "reality". There is thus a certain complementarity between these two types of approaches.

\subsection{Econometric studies}

If numerous econometric studies analyse the behaviour of investors on markets before and during currency crises, few of them are strictly dedicated to coordination game. More precisely, the empirical literature has identified two main points related to coordination game: 
- on the one hand, the behaviour of fundamentals does not allow to pinpoint the exact timing of the crisis. For instance, studying the process of acquisition of information during the Asian crisis between the beginning of 1997 and the end of May 1998, Kaminsky and Schmukler (1999) ${ }^{5}$ show that one-day swings on financial markets cannot be explained by economic and political news but are driven by herd behaviour;

- on the other hand, the influence of information dispersion on the likelihood of speculative attack is studied by Tillmann $(2004)^{6}$. His main result is the following: the higher the degree of heterogeneity between domestic and international investors, the higher the likelihood of currency crisis. As a result, not only the amount of information matters, but also the distribution of information. The latter observation means that measures which reduce the disparity of information, i.e. more transparency, can lower the probability of crisis.

From an empirical perspective, one of the main implications of coordination games is to estimate the effects of the precision of public and private information on the likelihood of speculative attacks. Previous empirical studies say nothing on this question. The incidence of public and private information on currency crises has been estimated by Prati and Sbracia (2002) and by Bannier (2005b). These studies are closely linked. Both are based on Morris and Shin's theoretical framework. Both try to disentangle the respective effects of the precision of public and private information. Finally, the two studies use the Consensus Economics to estimate the forecasts of investors. These studies differ mainly in their respective samples (six Asian countries for Prati and Sbracia; the Mexican crisis for Bannier) and in their estimation methods. After reviewing their methodology, we present their main results.

\subsubsection{Methodology}

In Prati and Sbracia's (2002) model, the likelihood of speculative attacks depends on three parameters: the mean of speculator's expectations about the fundamentals, the precision of public information, and the precision of private information. The testable implications of their theoretical model are summarized in the following specification:

$$
E R P_{t}=\gamma_{0}+\gamma_{1} f_{t-1}^{e}+\gamma_{2} \sigma_{t-1}^{e}\left(f_{t-1}^{e}-\underline{\gamma}\right)+\gamma_{3} e_{t-1}+\varepsilon_{t}
$$

\footnotetext{
${ }^{5}$ The authors consider only the days of market jitters defined as "the twenty largest one-day changes (downturns or upturns) in each country's stock market prices" (Kaminsky and Schmukler (1999) p.540). Their sample includes nine countries: Hong-Kong, Indonesia, Japan, Korea, Malaysia, Philippines, Singapore, Taiwan, and Thailand.

${ }^{6}$ The author considers the cases of the French Franc and the Italian Lira during the 1992 crisis. Tillman proposes a measure of the disparity of information founded on closed-end country fund prices and their underlying net asset value. Differences between fund prices and net asset values represent country fund premium or discount. They reflect the degree of information asymmetry on international markets. Domestic investors are assumed to be well-informed while international investors are badly informed.
} 
where $E R P$ is the measure of exchange rate pressure ${ }^{7}, f^{e}$ the mean of the individual forecasts, $\sigma^{e}$ the variance of the individual forecasts, $\underline{\gamma}$ the threshold separating "good" from "bad" expected fundamentals, and $e$ the level of the exchange rate.

The parameter $\gamma_{1}$ is negative because an improvement in the expected fundamentals reduces the pressures on the exchange rate. The effect of an increase in the dispersion of individual forecasts, that is an increase in $\sigma^{e}$, depends on the expected fundamentals and the source of uncertainty. The parameter $\gamma_{2}$-meaning an increase in the exchange rate pressures- will be positive in two situations:

- if increases in $\sigma^{e}$ are mainly explained by more imprecise public information and if, at the same time, speculators expect "good" fundamentals (i.e. if $f_{t-1}^{e}>\underline{\gamma}$ );

- if increases in $\sigma^{e}$ are mainly due to changes in the precision of private information and if, at the same time, actual and expected fundamentals are either both sufficiently good or both sufficiently bad. If increases in $\sigma^{e}$ are mainly due to changes in the precision of private information and if, at the same time, either the actual fundamentals are good (bad) and the expected fundamentals are bad (good), then the parameter $\gamma_{2}$ is negative. The variation of exchange rate over time exerts an influence on the exchange rate pressures even if $f^{e}$ and $\sigma^{e}$ are unchanged. This effect is measured by the parameter $\gamma_{3}$ which is expected to be positive ${ }^{8}$.

The specification (7) is tested only for the forecasts of GDP-growth, both for reason of date availability and because no other macroeconomic variables are significant when GDP-growth is included. The econometric study by Bannier (2005b), dedicated to the Mexican peso crisis of 1994-95, proposes a two-dimensional index of information -based on GDP-growth and currency reserves forecasts held by the central bank ${ }^{9}$ - in order to estimate the influence of different sources of uncertainty, i.e. private and public.

The estimated equation is the following:

$$
E R P_{t}=\delta_{0}+\sum_{j} \delta_{1 j} f_{j}^{e}+\sum_{j} \delta_{2 j} \sigma_{j}^{e}\left(f_{j}^{e}-T H R_{j}\right)+u_{t}
$$

where $E R P$ is the measure of exchange rate pressure, $f_{j}^{e}$ the mean of forecasts regarding specific economic variables $j, \sigma_{j}^{e}$ the standard deviation regarding specific economic variables $j, T H R$ the threshold separating "good" from "bad" expected fundamentals, and $u$ the error term.

\footnotetext{
${ }^{7}$ The exchange rate pressure is the sum of three indicators: the percentage depreciation of the domestic currency against the dollar, the fall in international reserves, and the short-term real interest rate.

${ }^{8} e$ is high when the exchange rate is appreciated.

${ }^{9}$ These two macroeconomic variables are statistically significant in the context of the Mexican crisis. Bannier (2005b) tests other macroeconomic variables but they are insignificant except budget balance in some specifications. As she uses GDP-growth and currency reserves forecasts for the pre-crisis and post-crisis periods, we consider only these two variables here.
} 
The parameter $\delta_{1}$ has a negative sign: the higher the expected fundamentals, that is the better the market sentiment, the lower exchange rate pressures. As in Metz (2002), the market sentiment and the source of uncertainty determine the sign of $\delta_{2}$. It will be positive in the following situations:

- a lower precision of public information increases the exchange market pressures either when market sentiment is very optimistic, that is $\left(f_{j}^{e}-T H R_{j}\right)>0$, suggesting an increasing effect of public information, or when market is pessimistic, that is $\left(f_{j}^{e}-T H R_{j}\right)<0$, expressing a decreasing effect of public information;

- a lower precision of private information leads to an increase in exchange rate pressures if actual and expected fundamentals are either both sufficiently good or both sufficiently bad.

$\delta_{2}$ will be negative in case of lower precision of private information if market sentiment is optimistic and actual fundamentals turn out to be bad or vice versa.

In order to distinguish between uncertainty originated from public information and from private information, Bannier (2005b) observes that while the Mexican authorities regularly and timely spread information on GDP-growth, the evolution of international reserves was hardly disclosed. She thus assumes that GDP forecasts are mainly driven through public information and international reserves forecasts -more strongly based on individual interpretations- through private information.

\subsubsection{Main results}

Prati and Sbracia (2002) consider the case of Thailand, Korea, Indonesia, Singapore, and Hong-Kong from January 1995 to May 2001. Their results are consistent with the theory. First, exchange rate pressures decrease with an improvement in the expected level of GDP-growth. Second, the dispersion of GDP-growth forecasts increases the exchange rate pressures when expected growth is relatively high. Finally, the estimation of the threshold separating "good" from "bad" expected growth shows that uncertainty about GDP-growth has contributed to increase exchange rate pressures in the precrisis period

The estimated period of Bannier's study is March 1993 to December 2000. She distinguishes two subperiods with slightly different results:

- In the pre-crisis sample (March 1993-December 1994), as expected by the theory, an improvement in the market sentiment, that is good GDP forecasts and international reserves forecasts, decreases exchange rate pressures. Broadly speaking, it appears that information dispersion, i.e. information uncertainty, leads to an increase in exchange rate pressures. But the main point is to identify what kind of uncertainty, public or private, has exerted the stronger influence on this result. When expected and actual fundamentals are compared, the striking result is that they scarcely coincided. In addition, in the months up to the crisis, we observe on the one hand, a decreasing uncertainty on GDP-growth and more pessimistic markets (recall that GDP-growth is supposed to be mainly public information) and on the other hand, an increasing uncertainty on international reserves and more optimist markets 
(international reserves forecasts are supposed to be more driven by private information). Regression results show that the increasing uncertainty on GDP-growth and international reserves exerts a destabilizing influence on the exchange rate regime ${ }^{10}$. As a consequence, "uncertainties should have been driven by public information" (Bannier (2005b) p.19);

- In the post-crisis sample (January 1995-December 2000), theoretical predictions remain satisfied: market sentiment has the same negative influences. Uncertainties regarding international reserves forecasts have the same positive impact as in the pre-crisis sample, but it is not the case for GDP growth forecasts. Indeed, this variable has a negative impact instead of a positive one as in the precrisis sample. Results cannot allow to distinguish what type of information -public or private- has driven uncertainty in the aftermath of the peso crisis. The reason is that, contrary to the pre-crisis period, expected and actual evolutions of economic variables coincided between January 1995 and December 2000.

Table 2 presents a synthesis of the econometric studies.

Table 2 Econometric results on the Exchange Rate Pressures (ERP): summary.

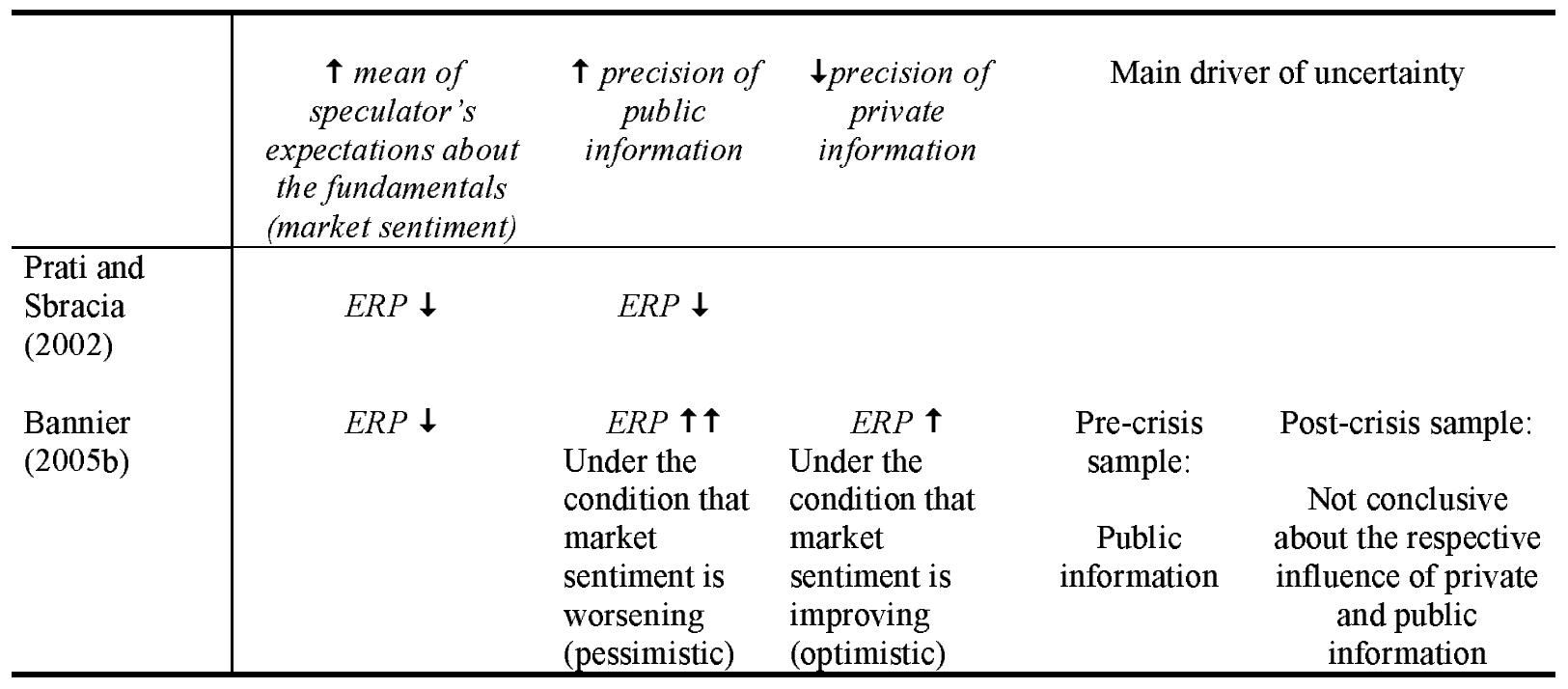

One of the main drawbacks of the Prati and Sbracia's study is to estimate a one-dimensional index of information, that is the forecasts of the GDP-growth. As a consequence, if the authors can estimate the incidence of informational uncertainty on speculative attacks, they cannot identify the respective effects of public and private information. The contribution of Bannier (2005b) allows us to disentangle between the influences of public and private information respectively. This study allows us to draw some lessons about the policy of information divulgation by the authorities. In the case of Mexico, it appears that neither information on GDP-growth nor information dissemination about currency reserves have exerted a stabilizing influence on the exchange rate regime. Bannier stresses that the outcome -stabilizing or destabilizing- of the information policy depends on the market sentiment

\footnotetext{
${ }^{10}$ Their coefficients are positive in the regression meaning an increase in the ERP.
} 
(optimistic versus pessimistic): there is an interaction between the way in which information is disseminated and the market sentiment. Taking together these two empirical studies allow to identify which type of piece of information -public or private- exercises a determining influence on the occurrence of an exchange rate crisis. But they do not allow to establish clear conclusions on the effects of the policy of transparency. It is necessary to be prudent in the interpretation of the results. Indeed, the preceding conclusions are valid only if the output is correlated with the fundamentals that determine the decision of devaluation, and independent of the decision of devaluation itself. Numerous models of exchange rate crises show that this is not the case. This link between exchange rate crises and output is one of the main features of the so-called third generation and sudden-stop models (see for example Bensaïd and Jeanne (1997) and Aghion, Bacchetta and Banerjee (2001)).

\subsection{Experimental studies}

Whereas they do not directly rely on real data, experimental studies present the advantage to eradicate any bias related to interferences with various variables of the "real world". While Cabrales, Nagel and Armenter (2003) are the first to present an experiment on global games, only two studies are directly applied to the speculative attack game: first Heinemann, Nagel and Ockenfels (2004) and second Cornand (2005) ${ }^{11}$. The framework is very similar in both cases. While Heinemann et al. consider the speculative attack game with common information (CI) on the one hand and private information (PI) on the fundamental state of the economy on the other, Cornand analyses simultaneous noisy private and common informational signals (PCS), on the one hand, and two noisy common signals (TCS) on the other ${ }^{12}$. These studies are complementary and enable us, to a certain extent, to address the question whether public information destabilises the economy.

\footnotetext{
${ }^{11}$ There are a few other studies that can be related to these two papers, but that are not directly applied to the standard static speculative attack game from which our analysis in section 1 is derived. In a debt crisis analysis, Anctil et al. (2004) propose to explore whether transparency can help decentralized decision makers to coordinate efficiently, when they face both strategic and fundamental uncertainties; their experiment mitigates the common belief according to which increased transparency is always desirable (see Walther (2004) for a comment, especially on their interpretation of transparency). Even though they aim at testing the informational structure with common and private information, Anctil et al. (2004) consider public information as a strict prior, while Cornand (2005) gives a public signal to agents that is distinct from the prior distribution of the fundamental state. By contrast to Heinemann, Nagel and Ockenfels (2004) and Cornand (2005), their experimental framework does not allow for (at least partial) continuity of actions and their design is contextualized. More recently, Cheung and Friedman (2005) experimentally test the impact of continuous time, size asymmetries and various amounts of public information in a dynamic speculative attack model.

${ }^{12}$ To be able to compare the results of her experiment to the results of Heinemann et al., Cornand drew a protocol as close as possible to theirs with only slight modifications, which do not have any impact on the unfolding of the game. The main change concerns the two treatments that are envisaged (simultaneous public and private information, and common multiple information).
} 


\subsubsection{Methodology}

In both experiments, 15 subjects per session (respectively 25 sessions in Heinemann et al. and 20 in Cornand) had to decide (160 times in total per session) between two alternative choices (A or B) ${ }^{13}$.

- Action A represents the safe choice, giving a positive and constant payoff $T$, which can be interpreted as the fact to avoid the costs linked to a speculative attack; it is a stated payoff. The two steps of each session were differentiated by the payoff linked to the choice A: in half of the sessions they started with $T=20$, then they took $T=50$ at the second stage; in the other sessions, they reversed the order.

- Action $\mathrm{B}$ is the risky action and can be interpreted as the attack, giving a payoff $Y$, if the number of subjects choosing B exceeds a certain threshold $a(Y)=15(80-Y) / W$, and 0 otherwise (the formula was given in the instructions, but also explained by an example and a table) ${ }^{14}$. Action $\mathrm{B}$ can thus give a positive payoff to the agent if a sufficient number of players chooses $B$ (this payoff is a function of the number of attacking agents but also of the fundamental value), and 0 otherwise.

For each situation, the state $Y$ is randomly selected from a uniform distribution on the interval $[10,90]$. The different treatments were constructed as follows ${ }^{15}$ :

- In common information sessions (Heinemann et al.), players precisely knew the value of $Y$ and knew that everyone shared this information.

- In private information sessions (Heinemann et al.), each agent received a private signal. Signals $X_{i}$ were randomly selected from a uniform distribution on the interval $[Y-10, Y+10]$ for each player separately; the received value was thus potentially different for each subject. Subjects knew that everyone of them only received private information and they shared the knowledge of the random process.

- In simultaneous noisy public and private information sessions (Cornand), each subject received a private signal $X_{i}$ randomly selected with a uniform distribution on the interval $[Y-10, Y+10]$ and all the subjects received on top of that the same signal $Z$ also randomly selected on $[Y-10, Y+10]$; the private value $X_{i}$ received by each agent was potentially different whereas the value $Z$ was identical for every agent; everyone knew this structure and shared the knowledge of the random process.

- In two public information sessions (Cornand), all the agents received two common signals $Z_{1}$ and $Z_{2}$ and knew that all participants received these two signals with certainty; each signal was randomly selected with a uniform distribution on the interval $[Y-10, Y+10]$ and everyone knew this structure and shared the knowledge of the random process.

\footnotetext{
${ }^{13}$ Note that the authors reversed the payoffs of the game to render its understanding easier for the subjects: a higher $Y$ corresponds to a lower state of the economy likely to give a higher payoff when an attack succeeds and conversely.

${ }^{14}$ In 4 sessions Heinemann et al. applied $W=100$ while in the others $W=60$; Cornand only applied $W=60$.

${ }^{15}$ The rules of the game including the structure of uncertainty were common information among the subjects of each session. The experiment avoided any connotation that might be associated with "speculation" or "attack": subjects were simply asked to choose between two actions A and B.
} 


\subsubsection{Main results}

The laboratory experiment on coordination games with private and public information by Heinemann et al. indicates that there are only small differences in the perception of public and private signals. Their data reject the hypothesis that predictability is reduced with public information. Instead, they show that agents' behaviour is very similar in both informational contexts. On the other hand, Cornand shows that subjects put a larger weight on the public signal if they receive a private and a public signal about the payoff of a coordination game. Thereby, the focal potential of public information cannot be neglected. In what follows we give more details in terms of probability and predictability of an attack and in terms of coordination.

\subsubsection{Probability of successful attacks}

The higher the threshold to success, the smaller is ex ante probability for states, at which subjects succeed to play B. This is interpreted as a lower prior probability for speculative attacks that enforce devaluation. Heinemann et al. show that the prior probability of an attack is higher in the case of CI than in that of PI. Independently, Cornand finds that while subjects tend to coordinate more on the public signal under PCS, the probability of a crisis is always higher in the TCS treatment comparatively to the PCS treatment. We can say that the result by Heinemann et al. with respect to the probability of an attack is robust to the addition of a public signal in each treatment. Overall, there is clear evidence from both studies: the treatment that typically increases the probability of an attack is the common information case. We can even ordinate the treatments with respect to their impact on the probability of an attack.

\subsubsection{Predictability of attacks}

To consider whether there is any difference in predictability of thresholds related to the information condition, the standard deviations of average thresholds across sessions can be compared. Whereas the dispersion of thresholds across different sessions is about the same for both information conditions in Heinemann et al., Cornand gets a small difference between her two treatments -namely predictability of successful speculative attacks is slightly higher in PCS sessions than in TCS ones. This reverse in results might be explained by the fact that the single common signal serves as a coordination point, similarly to the CI treatment in Heinemann et al.. The fact to have a private signal accompanying the public one avoids the self-fulfilling beliefs that might be disturbing. Anyway, decentralised information (i.e. several sources of information or several signals) tends to reduce the predictability of attacks. This result is even more significant for the TCS treatment, probably because of the same selffulfilling nature of both common signals.

\subsubsection{Coordination Failures}

The differences in coordination can be measured by the width of the interval within a session between the highest state up to which action B (the risky action) always failed and the lowest state from which 
on action B was always successful. With a continuous space for states and signals, Heinemann et al. observe that with $\mathrm{CI}$, the coordination of agents was much better achieved than with PI. Cornand finds no significant difference between TCS and PCS treatments. The rationale behind this result is that, in the PCS treatment, the public signal serves as a focal point for the beliefs of the group as a whole, but it also conveys less precise information on the underlying fundamentals than the two public signals in the TCS sessions. As a consequence, on a global comparative level, having only one public (and unmistaken) signal favours coordination. The existence of several focal points (several public signals) perturbs coordination. The presence of decentralised information always leads to a worse result. Nevertheless, this comparison is plagued by the fact that the precision of the common information treatment is perfect in Heinemann et al. whereas the other informational structures are of imperfect information.

Table 3 gives a synthesis of the results of the experimental studies with respect to the probability of an attack, the predictability of an attack and the way participants coordinate.

Table 3 Synthesis of experimental studies (comparisons inside treatments, between treatments, between studies and between empirics and theory).

\begin{tabular}{|c|c|c|c|c|}
\hline Studies & & Probability of an attack & $\begin{array}{l}\text { Predictability of an } \\
\text { attack }\end{array}$ & Coordination \\
\hline \multirow{2}{*}{$\begin{array}{l}\text { Heinemann } \\
\text { et al. } \\
(2004)\end{array}$} & $\mathrm{CI}$ & Relatively high probability & \multirow{2}{*}{$\begin{array}{l}\text { High compared to other } \\
2 \text { treatments (and also } \\
\text { compared to theory) }\end{array}$} & Better achieved \\
\hline & PI & $\begin{array}{l}\text { Always lower probability } \\
\text { than in other } 3 \text { treatments }\end{array}$ & & Least efficient \\
\hline \multirow[t]{2}{*}{$\begin{array}{l}\text { Cornand } \\
(2005)\end{array}$} & TCS & $\begin{array}{l}\text { Always higher probability } \\
\text { than in other } 3 \text { treatments }\end{array}$ & \multirow{2}{*}{$\begin{array}{l}\text { Better in PCS than TCS } \\
\text { treatment (owing to the } \\
\text { focal potential of a } \\
\text { single public signal) }\end{array}$} & $\begin{array}{l}\text { Good but less efficient than in } \\
\text { CI }\end{array}$ \\
\hline & PCS & Relatively low probability & & $\begin{array}{l}\text { Between TCS and PI and } \\
\text { inside the treatment better } \\
\text { achieved on the public signal }\end{array}$ \\
\hline
\end{tabular}

If those experiments tend to validate the global game theory ${ }^{16}$, it however appears that the destabilising effects of public information, linked with the existence of multiple equilibria, can be less severe than what is predicted theoretically.

\footnotetext{
${ }^{16}$ Hellwig (2002b) points out that the theoretical findings on the effects of public information are valid only if the agents' preference structure is approximately common knowledge. When there is a lack of common knowledge about agents' preferences (or more generally decision processes, as can be assumed in the experimental laboratory), the implication that public information disproportionately affects decisions and leads to instability breaks down. Therefore, to properly test the theoretical implications of global games in the experimental lab, one needs to control for the information structure regarding preference. While it is not possible to control preferences in an experiment, Heinemann et al. could get close to it, by controlling for the individual degree of risk aversion. Indeed, for very small payoffs, subjects behaved almost risk neutral, whereas for very high ones, they behaved risk averse (as this could be seen in the rise in thresholds). Consequently paying subjects depending on performance induces preferences that are in line with the theory on test.
} 


\section{Evaluation and perspectives: a critical analysis}

In this part, we show that the confrontation between theoretical results and empirical studies is not completely satisfying. Therefore, we suggest some guidelines for future research in order to better catch stylised facts on the one hand and to better evaluate the theory on the other. In terms of transparency, we are able to go beyond previous contradictions, i.e. to positively link transparency in public information and transparency in private information.

\subsection{Theoretical $v s$. empirical studies}

Beyond methodological problems, there is an imperfect connection between theoretical and empirical results on the one hand and a lack of empirical studies on the other.

Both types of empirical studies (experimental and econometrical ones) tend toward a certain validation of the respective theoretical predictions. First, Heinemann et al. (2004) find that the sole public information increases the probability of an attack compared to the situation with private information uniquely. In that sense, it could be instability increasing. Secondly, Bannier (2005b) shows that the stabilising or destabilising effects of an increase in the precision of (either public or private) information depends on the market sentiments (pessimistic/ optimistic). This result confirms the theoretical models based on the interaction between public and private information. Finally, in the same context, Cornand (2005) finds that coordination is better achieved on the public signal, which bears the theory out as it predicts that the public signal plays a focal role. Yet, this validation is limited to a certain extent, as shown in Table 4 below.

First, the empirical analysis seems insufficient. In particular, a main part of the theory does not have its empirical counterpart: the analysis in terms of private / public information relative precision. Neither econometric analyses nor experimental studies have managed to catch this main feature of global game models. To be able to better test the theory, the role of the (relative) precision of private $v s$. public signals should be evaluated by experimental economics, especially by getting an approximate level of the threshold relative precision ratio up to which the economy is destabilised and from which on the economy is stable or by looking for the approximate precision ratio for which both types of signals have the same multiplier effects. This would in particular permit to better calibrate theoretical models (and ameliorate simulations which would thus be drawn from "real" data). 
Table 4 Synthesis of empirical vs. theoretical predictions in terms of informational disclosure policy.

\begin{tabular}{l|l}
\hline Theoretical predictions & Empirical evidence \\
\hline &
\end{tabular}

One public signal (Obstfeld (1996)).

$\rightarrow$ Destabilisation:

The public signal is a focal point but can provoke an overreaction of agents.

$\rightarrow$ Multiple equilibria due to common knowledge imply the absence of result in terms of probability and predictability of an attack.

One private signal (Morris and Shin (1998);

Heinemann and Illing (2002))

$\rightarrow$ Stabilisation if private information precise enough:

The presence of private information leads to higher order beliefs, which prevent from overreaction of agents to any signal.

$\rightarrow$ Increasing the precision of private signals always reduces the probability of an attack.

One public signal and one private signal (Morris and Shin (2004)).

$\rightarrow$ Stabilisation if private information precise enough compared to public information:

The public signal serves as a focal point while at the same time the presence of private information avoids agents' overreaction.

$\rightarrow$ Increasing the precision of private and/or public signals can have ambiguous effects in terms of probability of an attack (Sbracia and Zaghini (2001), Metz (2002), Bannier and Heinemann (2005)).
- There is apparently no overreaction (Heinemann et al. (2004)).

- Public information increases the probability of an attack, but does not reduce its predictability (Heinemann et al. (2004)).

- Increasing the precision of public information is stabilising (Prati and Sbracia (2002)).

$\rightarrow$ Public information does not necessarily increase instability.

- One private signal does not imply more stabilisation than one public signal (Heinemann et al. (2004)).

- Increasing the precision of private information reduces the probability of an attack (Bannier (2005b)).

- Stabilisation seems to be better achieved on the public signal (Cornand (2005)).

- An analysis of the impact of the relative precision of signals is missing.

The difficulty to distinguish "pure" public from "pure" private information in econometric studies as Prati and Sbracia (2002), solved by Bannier (2005b) to a certain extent, strengthens this idea. And such a problem also prevents from analysing a main part of the speculative attack game. Some information is both public and private. Indeed, when central banks use only cheap talks -for instance, speeches by governors- this way of communication is fragmented. It does not necessarily lead to the elaboration of a common framework across private agents. As a result, if we take into account the 
probable different interpretations by the agents, such public signals become in fact private ones. It is very difficult to disentangle public and private information in this context.

In what follows, we analyse some theoretical extensions which can be useful to solve those problems. Our theoretical analysis sheds light on informational structures which free themselves from the strict dichotomy between public information on the one hand and private information on the other.

3.2 Re-thinking the articulation between public and private information: some recent theoretical insights

We aim at rethinking the articulation between public information and private information to better evaluate the pros and cons of higher transparency. Indeed, although public information and private information are strictly distinguished in theory, empirical evidence suggests that they have the similar nature. Recent theoretical studies have made progress in this respect though the literature is still in its infancy. Firstly, an increasing part of the literature has focused on how to integrate endogenous information into global games. Secondly, the notion of public information can be refined.

\subsubsection{Introducing endogenous information}

In a comment on Morris and Shin (2000), Atkeson (2001) firstly criticises the lack of a theory of prices linked with the absence of formalised markets in global games especially applied to currency crises. Atkeson stresses the role of prices to coordinate actions in decentralized markets: prices aggregate information across individuals and then allow the coordination of their actions.

In this line of research, Angeletos and Werning (2004) show that even if there exists a small noise in private information, multiple equilibria are present on the markets because all relevant information is in fine integrated in prices. An increase in the precision of private information regarding the fundamentals implies that agents are more sensitive to their private signals to take positions in the markets. Indeed, an increase in the precision of private information produces two conflicting effects: (i) directly, it increases the dispersion of information and therefore makes coordination more difficult; (ii) indirectly, it increases the precision of public information, once we take into account the role of prices as information aggregator, and thus facilitates coordination. Consequently, if prices integrate the different actions of the agents, the aggregation process leads to a rise in the sensitivity of the public indicator of others' actions -e.g. the prices of traded assets- to variations of the underlying fundamentals. "As a result, the precision of the endogenous public information is increasing in the precision of the exogenous private information" (p.4).

Also aiming at rendering public information endogenous, Angeletos, Hellwig and Pavan (2003) investigate "the ability of a policy maker to influence market expectations and control equilibrium outcomes in environments where market participants play a coordination game with information heterogeneity" (p.2). The authors consider the signalling effect of interest rate changes by the central bank. Indeed, considering that it is costly to raise the interest rate, the central bank will not change the 
interest rate in two situations: (i) when fundamentals are too strong to induce a speculative attack; (ii) when fundamentals are too weak to allow a successful defence of the exchange rate regime. As a result, a rise in interest rate reveals that the fundamentals are in an intermediate situation. Hence, contrary to Morris and Shin, again the presence of noisy signals does not prevent multiple equilibria. However, this result "is not about the possibility of multiple continuation equilibria in the coordination game that follows a given realization of the public signal; it is rather about how endogenous coordination in the market makes the effectiveness of the policy depend on arbitrary market sentiments and leads to multiple equilibria in the signalling game" (p.18). But if endogenous signalling leads to multiple equilibria, the equilibrium set is reduced by information heterogeneity compared to a common knowledge framework. The policy maker will raise the interest rate only for a small region of moderate fundamentals, and "the "anxiety region" vanishes as the information in the market becomes precise" (p.4).

What are the economic policy implications of rendering information endogenous? If previously mentioned models do not explicitly derive any prescription and rather deal with equilibrim uniqueness $v s$. multiplicity, it is precisely because in such a context informational policy has no role. Even in the presence of private signals, the market is able to aggregate all relevant information and in fine gives rise to public information via prices. Public information (even quite precise) is destabilising (as it leads to multiple equilibria).

This type of argumentation (so to say the endogeneisation of public information) raises some questions. Especially, to what extent do prices -for instance interest rates differential- convey information on the state of fundamentals? An extensive literature -founded on the microstructure of exchange rate markets or the empirics of the exchange rate crises- shows that prices do not reflect with a high precision the true state of the economy ${ }^{17}$. For example, empirical studies on exchange rate crises show that interest differentials do not jump immediately before an attack. In addition, the pesoproblem suggests that the interest differential is not necessarily a good indicator of future events. Recall that the peso problem arises when markets anticipate a future shift in policy that is not materialized within the sample period. And, except in the ERM case, interest differentials integrate not only expectations of depreciations, but also risk premia. Angeletos and Werning (2004) take the example of the Argentine crisis in 2001-2002 to justify their approach. One year before the collapse of the currency board in January 2002, a fall in peso and dollar deposits, an increase of the risk premium on Argentine international sovereign bonds and depreciation of the peso-forward rate have been observed. In fact, the Argentine crisis is typically a fundamental type exchange rate crisis, not a selffulfilling one. As a consequence, their argument applies in this precise context, while it may not in

\footnotetext{
${ }^{17}$ Using survey data on traders' expectations, Eichengreen and Wyplosz (1993) show that the ERM exchange rate crises of 1992-93 were unexpected even one month before they occurred. In the case of the Mexican peso (1994) and the Thai bath (1997), Goldfajn and Valdes (1998) find that exchange rate expectations measured by interest differentials largely underestimated the size of the devaluation at three and six months horizon. More recently, Berg and Patillo (1999) underline that fundamentals cannot predict very well future speculative attacks.
} 
others. More generally, if prices aggregate all private information, and prices are common knowledge, then there is no private information left; this goes back to Radner (1979) who shows that private information is revealed by markets in a rational expectations equilibrium. This requires that agents know the equilibrium and that there is one-to-one relation between information and prices, which does not apply in the currency crises case: the central bank does not publish the amount of reserves, and thus, uncertainty on the shadow exchange rate remains.

Another way of linking private and public information while giving a role to the informational policy is to refine the definition of public information.

\subsubsection{Redefining the notion of public information}

To redefine the notion of public information, we base our analysis on recent works by Lindner (2005) who considers that more transparency generates better private information as each market participant utilizes public information according to his own private information and by Cornand and Heinemann (2004, 2005) who suggest to consider first several public signals which precision is private information and second $p$-common signals.

Lindner (2005) stresses that more public information does not necessarily lead to common knowledge by considering an economy with two time periods. In period 0 , the central bank publicly announces its own assessment about the fundamental state of the economy $\left(\theta_{0}\right)$. In period 1 , the traders must decide to attack or to hold the currency. The success of the attack depends on the new central bank's assessment $\theta_{1}$, which is not observable by the agents. To estimate it, agents have two sources of information: the initial public central bank's assessment $\theta_{0}$ and their own private information $\left(y_{i}\right)$ about the new assessment. The weight given to each type of information in the decision making process is function of their respective variances: the higher (lower) the variance, the smaller (higher) the weight of the information. Lindner defines more transparency as more information given by the central bank to the public about how it has come to its assessment of the fundamental strength of the economy. The main point is the following: each trader will privately benefit from this higher transparency in updating her initial private beliefs. As a consequence, more information communicated by the central bank does not generate a common knowledge situation, but makes private information more precise. The fact that traders react differently to the same public signal rests on their respective expertise. Indeed Lindner assumes that some traders are experts on the real sector of the economy while others are experts on the financial sector. In this context, more transparency means that the central bank produces more information on both the real and the financial sectors, but traders are able to integrate exactly or not this new information in their beliefs according to their expertise. For the other information for which the trader is not expert, she uses the central bank's estimation in period 0 . So, the same sets of public signals leads to different updating processes.

In the same spirit, Cornand and Heinemann (2005) consider that differences in the treatment of public information by private agents avoid common knowledge and therefore avoid self-fulfilling beliefs 
equilibria. Contrary to Lindner, to model this idea, they notice that there exists on the exchange rate market a great many channels (media, newspapers or other informational channels), which disclose information publicly. Indeed, all provide information on the state of the economy, but more or less accurately. Cornand and Heinemann introduce multiple sources of public information in a second generation speculative attack model. They assume that all announcements are common knowledge, but the variances of their distributions are private information. Agents have different beliefs about these variances. In a Bayesian update, posterior beliefs are weighted averages of the announcements, where relative weights are given by the relative precision (the inverse of the variance) of announcements. These weights differ between agents ${ }^{18}$. So even if all agents share the same information, multiple public signals permit to take into account differences in the treatment of information as soon as the precision of these signals is private information: agents' posterior beliefs can be different and agents are aware of these differences. They show that this model has a unique equilibrium, if there are sufficiently many or strong announcements that hint at states at which either attacking or not-attacking are dominant strategies. When the number of agents approaches infinity, the distribution of posterior beliefs becomes common knowledge. This turns the private-information game into a private-value game, for which there is a unique equilibrium, provided that there is a sufficient mass of agents for whom either action is a dominant strategy. By creating information disparities between agents, multiple sources of public information of unknown precision can avoid self-fulfilling beliefs equilibria. Such a framework can explain why and how private beliefs can differ, even when all the information about fundamentals is publicly disclosed. In terms of economic policy, they show that the central bank should benefit from at least two tools: if used appropriately, number (i.e. centralisation $v s$. decentralisation of information) and precision of signals can be effective at stabilising the economy in situations where it might be prone to self-fulfilling crises otherwise.

In a different coordination game closely related to Morris and Shin (2002), Cornand and Heinemann (2004) propose another manner with which to weaken the strict dichotomy between public and private information. They argue that intermediate concepts like common $p$-beliefs are better qualified to describe the state of minds after public announcements ${ }^{19}$. They thus relax the assumption of public information. Usually, public information comprehends two elements (that are not well distinguished): the fact that it is the same information; the fact that it is received with certainty. They propose to keep the first characteristic while abandoning the second one: public information is the same for everybody but everyone does not necessarily receive $\mathrm{it}^{20}$. In other words, the public signal is common $p$-belief in

\footnotetext{
${ }^{18}$ In other words, private information is defined as a subjective weighting (or subjective interpretation), by each agent privately, of different public signals, commonly observable but disclosed with a more or less high unknown degree of precision.

${ }^{19}$ An event is common $p$-belief among agents if all of them believe with at least probability $p$ that this event has occurred, all agents believe with at least probability $p$ that all others believe with at least probability $p$ that this event has occurred, and so on. See Monderer and Samet (1989).

${ }^{20} \mathrm{~A}$ possible interpretation for a real economy is also that there is always some probability that an agent misses an announcement or misunderstands it.
} 
the population as a whole. They thus propose a very particular definition of public information and explore another dimension of public information: the degree of publicity, i.e. the proportion of economic agents amongst whom a message is common knowledge. This feature avoids common knowledge among the whole population and generates a framework in which agents potentially get different signals. Their model shows that the degree of publicity is a powerful instrument of information policy. The policy implication in such a context is that restrictions to the number of receivers of public signals represent a more efficient tool to avoid precarious coordination effects than ambiguity of signals, thus questioning Morris and Shin's (2002) results. The rationale behind this result is linked with the reduction in agents' overreaction to sometimes imprecise (mistaken) public announcements. A low level of publicity reduces incentives to over-react to the public signal and limits the welfare reducing effect on higher-order beliefs: it combines the positive effects of valuable information for those who get it with a confinement of its threats by limiting the number of receivers. The central bank disposes of two different tools to conduct economic policy: the precision of information and the level of information disclosure. Both instruments are double-edged: higher precision improves the quality of private decisions by those who receive information and higher publicity enlarges the number of those who benefit from this information. At the same time, both instruments raise incentives to overweigh public signals.

These approaches have the merit to keep the heterogeneity of agents and to render account of recent crises that were not only fundamental-driven. More particularly, fundamentals play a role but there is a place for misinterpretation of some pieces of information. In this sense, they respond to the empirical view according to which fundamental explanations are found ex post but were to some extent not predictable. They also permit to deduce some coherent policy implications in terms of transparency (declined by precision, number and degree). Nevertheless those three models represent only some examples to better take into account the informational structure on the exchange rate market by questioning the strict dichotomy between public information on the one hand and private information on the other.

\section{Conclusion}

Transparency is a central and crucial issue of economic implications of coordination games under incomplete information applied to speculative attacks and more generally to any monetary or financial contexts. However, the confrontation between empirical and theoretical studies does not lead to any satisfying answer with regards to whether transparency is stabilising or not.

The proposed insights of this paper should help understand and evaluate the pros and cons of transparency. We have shown that it is necessary to adapt policy of information disclosure to a strategic environment. Informational policy should not be one-dimensional and restrict itself to pure and simple transparency that seems to be appropriate only in a decisional non-strategic framework. On the opposite, it should benefit from the existence of several tools, especially the precision, number and 
degree of publicity. Agents do not always over-react to public information. Indeed, from above two signals -which precision is not common knowledge- agents do not always have self-fulfilling beliefs. This gives a role to the precision of signals: apart from its degree, uncertainty on it can represent an effective tool for the central bank to control for the beliefs of the agents. In the case where there is only a single public signal (accompanied by a private one), over-reaction can also be avoided, but this time owing to a limited degree of publicity that limits the negative effects of publicity.

These policy prescriptions are in line with the empirical objection according to which it is not always obvious that there is a huge difference between public information on the one hand and private information on the other. Nevertheless, it would be relevant to empirically take into account the role of signals' precision and that of the degree of information disclosure to fully validate theoretical models.

\section{References}

Aghion P., P. Bacchetta and A. Banerjee, (2001), Currency crises and monetary policy in an economy with credit constraints, European Economic Review, 45, 7, pp.1121-1150.

Anctil R., J. Dickhaut, C. Kanodia and B. Shapiro, (2004), Information Transparency and Coordination Failure: Theory and Experiment, Journal of Accounting Research, 42, Supplement, p. 159-195.

Angeletos G.-M. and A. Pavan, (2004), Transparency of Information and Coordination in Economies with Investment Complementarities, American Economic Review (Papers and Proceedings), 94, 2, 91-98.

Angeletos G.-M. and I. Werning, (2004), Information Aggregation, Equilibrium Multiplicity and Market Volatility: Morris-Shin Meets Grossman-Stiglitz, Mimeo, July.

Angeletos G.-M., C. Hellwig and A. Pavan, (2003), Coordination and Policy Traps, NBER Working Paper Series, 9767, June.

Atkeson A., (2001), Discussion of Morris and Shin's "Rethinking multiple Equilibria in Macroeconomic Modelling", in B.S. Bernanke and K. Rogoff (eds), NBER Macroeconomics Annual 2000, The MIT Press, 2001.

Bannier C.E., (2005a), Privacy or Publicity - Who Drives the Wheel?, in F. Columbus (ed.): Contemporary Issues in International Finance, Nova-Publishers, New York, forthcoming.

Bannier C.E., (2005b), The Role of Information Disclosure and Uncertainty in the 1994/95 Mexican Peso Crisis: Empirical Evidence, forthcoming Review of International Economics.

Bannier C.E. and F. Heinemann, (2005), Optimal Risk Taking and Information Policy to Avoid Currency and Liquidity Crises, Journal of Institutional and Theoretical Economics, 161, pp.374391.

Bensaïd B. and O. Jeanne, (1997), The instability of Fixed Exchange Rate Systems when Raising the Nominal Interest Rate is Costly, European Economic Review, 41, 8, pp.1461-1478.

Berg A. and C. Pattillo, (1999), Are currency crises predictable? A test, IMF Staff Papers, 46, 2, pp.107-138.

Cabrales A., R. Nagel and R. Armenter, (2003), Equilibrium Selection through Incomplete Information in Coordination Games: An Experimental Study, Discussion paper, 601, Universitat Pompeu Fabra, Barcelona.

Cheli B. and P. Della Posta, (2002), Self-fulfilling Currency Attacks with Biased Signals: Morris and Shin's Model Reconsidered, University of Pisa, Mimeo. 
Cheung Y.-W. and D. Friedman, (2005), Speculative Attacks: A Laboratory Study in Continuous Time, Mimeo, July.

Cornand C., (2005), Speculative Attack and Informational Structure: An Experimental Study. Working Paper GATE 2004-07, forthcoming Review of International Economics.

Cornand C. and F. Heinemann, (2004), Optimal Degree of Public Information Dissemination, CESifo Working Paper, 1353, December.

Cornand C. and F. Heinemann, (2005), Speculative Attack and Multiple Sources of Public Information, Mimeo, January.

Eichengreen B. and C. Wyplosz, (1993), The Unstable EMS, Brookings Papers on Economic Activity, 1, pp.51-143.

Gai P. and H.S. Shin, (2003), Transparency and Financial stability, Financial Stability Review, 15, pp.91-98.

Geraats P., (2002), Central bank transparency, Economic Journal, 112, F532-556.

Goldfajn I. and R.O. Valdés, (1998), Are currency crises predictable?, European Economic Review, $42,3-5$, pp. $873-885$.

Heinemann F., (2002), Exchange Rate Attack as a Coordination Game: Theory and Experimental Evidence, Oxford Review of Economic Policy, 18, 4, pp.462-478.

Heinemann F. and G. Illing, (2002), Speculative Attacks: Unique Sunspot Equilibrium and Transparency, Journal of International Economics, 58, pp.429-450.

Heinemann F., R. Nagel and P. Ockenfels, (2004), The Theory of Global Games on Test: Experimental Analysis of Coordination Games with Public and Private Information, Econometrica, 72, 5, pp. 1583-1599.

Hellwig C., (2002a), Public Information, Private Information and the Multiplicity of Equilibria in Coordination Games, Journal of Economic Theory, 107, pp.191-222.

Hellwig C., (2002b), Imperfect Common Knowledge of Preferences in Global Coordination Games, Mimeo, UCLA, October.

Jeanne O., (2000), Currency Crises: A Perspective on Recent Theoretical Developments, Special Papers in International Economics, 20, International Finance Section, Department of Economics Princeton University, Princeton, New Jersey, March.

Kaminsky G.L. and S. Schmukler, (1999), What Triggers Market Jitters? A Chronicle of the Asian Crisis, Journal of International Money and Finance, 18, pp.537-560.

Kübler D. and G. von Weizsäcker, (2003), Limited Depth of Reasoning and Failure of Cascade Formation in the Laboratory, Review of Economic Studies, 71, pp.425-441

Lindner A., (2005), Does transparency of central banks produce multiple equilibria on currency markets?, forthcoming Scandinavian Journal of Economics.

Metz C.E., (2002), Private and Public Information in Self-Fulfilling Currency Crises, Journal of Economics, 76, 1, pp.65-85.

Monderer D. and D. Samet, (1989), Approximating Common Knowledge with Common Beliefs, Games and Economic Behaviour, 1, pp.170-190.

Morris S., (2002), Coordination, Communication and Common Knowledge: A Retrospective of the Electronic Mail Game?, Oxford Review of Economic Policy, 18, 4, pp.433-445.

Morris S. and H.S. Shin, (1998), Unique Equilibrium in a Model of Self-fulfilling Currency Attacks, American Economic Review, 88, 3, 587-597.

Morris S. and H.S. Shin, (2002), Social Value of Public Information, American Economic Review, 92, 5, December, pp.1522-1534. 
Morris S. and H.S. Shin, (2003), Global Games: Theory and Applications, in M. Dewatripont, L.P. Hansen and S.J. Turnovsky (eds), Advances in Economics and Econometrics: Theory and Applications, Volume One, Cambridge University Press, London, pp.56-114.

Morris S. and H.S. Shin, (2004), Coordination Risk and the Price of Debt, European Economic Review, 48, pp.133-153.

Morris S., H.S. Shin and H. Tong, (2005), Response to "Social Value of Public Information: Morris and Shin (2002) Is Actually Pro Transparency, Not Con", forthcoming American Economic Review.

Myatt D.P, H.S. Shin and C. Wallace, (2002), The Assessment: Games and Coordination, Oxford Review of Economic Policy, 18, 4, pp.397-417.

Nagel R., (1995), Unravelling in Guessing Games: An Experimental Study, American Economic Review, 85, 5, pp.1313-1326.

Obstfeld M., (1986), Rational and self-fulfilling balance-of-payments crises, American Economic Review, 76, 1, pp.72-81.

Obstfeld M., (1996), Models of Currency with Self-fulfilling Features, European Economic Review, 40, pp.1037-1047.

Prati A. and M. Sbracia, (2002), Currency Crises and Uncertainty about Fundamentals, IMF Working Paper, WP\02\3, January.

Radner R., (1979), Rational Expectations Equilibrium: Generic Existence and the Information Revealed by Prices, Econometrica, 47, pp.655-678.

Sbracia M. and A. Zaghini, (2001), Expectations and Information in Second Generation Currency Crises Models, Economic Modelling, 18, 2, pp.203-222.

Svensson L.E.O., (2005), Social Value of Public Information: Morris and Shin (2002) Is Actually Pro Transparency, Not Con, forthcoming American Economic Review.

Tillmann P., (2004), Information Disparities and the Probability of Currency Crises: Empirical Evidence, Economics Letters, 2004, 84, pp.61-68.

Walther B.R., (2004), Discussion of Information Transparency and Coordination Failure: Theory and Experiment, Journal of Accounting Research, 42, Supplement, p. 197-205.

Winkler B., (2002), Which Kind of Transparency? On the Need for Clarity in Monetary Policy Making, IFO Studies, 48, 3, 401-427. 